\title{
DO CLÁSSICO ÀS IDEIAS PEDAGÓGICAS: UMA LEITURA DA PEDAGOGIA DA AUTONOMIA, DE PAULO FREIRE
}

\author{
POR CHAMPOUDRY, A. C.
}

\section{RESUMO}

O presente texto tem por objetivo analisar as ideias pedagógicas de Freire presentes na obra Pedagogia da autonomia: saberes necessários à prática educativa, problematizando-a com base nas seguintes questões: De que maneira a obra Pedagogia da autonomia: saberes necessários à prática educativa pode ser considerada um clássico na formação de professores? Quais ideias pedagógicas presentes na Pedagogia da autonomia contribuem para pensar sobre essa questão? Parte-se da relação entre a concepção de clássicos defendida por Calvino (2007) e a apresentação das ideias pedagógicas desenvolvidas por Freire (1996) no livro, descrevendo-o como um clássico a ser lido no contexto atual. Utiliza-se a noção de clássicos elaborada por Calvino na obra Por que ler os clássicos? com base nas definições que contribuem para expor os significados de uma leitura clássica em educação. Como metodologia, utilizou-se a pesquisa bibliográfica da perspectiva de leitora que, apropriando-se (CHARTIER, 2001 b) das ideias do autor, produz elaborações de modo a contribuir para uma análise da obra. Ao entender a definição de clássico como aquele que nunca terminou de dizer o que tinha para dizer, aquele cuja releitura é uma leitura de descoberta como a primeira e aquele que deixa ruídos em tempos e contextos mesmo que estes sejam incompatíveis com as suas ideias, reafirma-se a leitura do autor e da obra em questão como um clássico que se torna imprescindível no contexto educacional atual em que reiteradas ofensas são imputadas ao ato de educar, às instituições educativas e aos sujeitos que nela estão inseridos.

\section{PALAVRAS-CHAVE}

Leitura; Autonomia; Formação Docente

\section{ABSTRACT}

This text aims to analyze the pedagogical ideas of Freire present in the work Pedagogy of autonomy: knowledge required for educational practice problematizing it from the following questions: How does the work of Pedagogy of autonomy: knowledge required for educational practice can be considered as a classic in teacher training? Which pedagogical ideas present in the Pedagogy of autonomy contribute to thinking about this issue? It starts from the relationship between the conception of classics defended by Calvino (2007) and the presentation of the pedagogical ideas developed by Freire (1996) in the book, describing it as a classic to be read in the current context. The notion of classics used was that elaborated by Calvino in the book Why read the classics? from the definitions that contribute to expose the meanings of a classical reading in education. As methodology, the bibliographic research was used from the perspective of reader who, appropriating (CHARTIER, 2001b) of the author's ideas, produces elaborations in order to contribute to an analysis of the work. When understanding the definition of classic as the one who never finished saying what he had to say, the one whose rereading is a discovery reading as the first and the one that leaves noises in times and contexts even if they are incompatible with his ideas, reaffirms the reading of the author and the work inquestion, as a classic that becomes indispensable in the current educational context in which repeated offenses are imputed to the act of educating, to the educational institutions and to the subjects that are inserted in it.

\section{KEYWORDS}

Reading; Autonomy; Teacher training

\footnotetext{
'Departamento de Educação II -UFMA (Universidade Federal do Maranhão)
} 
Introdução

A ideia para este texto surgiu durante as aulas da disciplina de História das Ideias Pedagógicas nas quais foram trabalhados teóricos da educação e suas ideias pedagógicas que, historicamente constituídas, contribuíram para consolidar conhecimentos acerca da história da educação e da própria pedagogia como ciência, a partir do estudo de obras consideradas clássicas para serem estudadas na formação de professores. A escolha pela obra de Freire ocorrev em função dos motivos que seguem: pelo tema da pesquisa que se desenvolve no doutorado em educação da Faculdade de Educação da Universidade de São Paulo (FEUSP), acerca da leitura entre a produção de conhecimentos e seu ensino no contexto da formação de professores; pelo período histórico da pesquisa em desenvolvimento, conforme será apresentado.

A investigação de que se trata tem por objetivo observar a produção de conhecimentos sobre leitura no contexto da formação de professores para os anos iniciais do ensino fundamental, em universidades maranhenses, no período que vai de 1996 a 2016. A definição por esse momento histórico se justifica pela promulgação da Lei n. 9.394/1996, que se constitui como a Lei de Diretrizes e Bases da Educação Nacional, e pela definição de um currículo nacional feito com a instituição dos Parâmetros Curriculares Nacionais (PCN) até o período de uma nova proposição de organização curricular nacional com a Base Nacional Comum Curricular (BNCC), em 2016. Pretende-se, por meio da investigação em relatórios de pesquisas desenvolvidas por professores, pelos trabalhos de conclusão de cursos (TCC) dos estudantes e pelos projetos de cursos de pedagogia, observar de que modo ocorreu a produção de conhecimentos sobre leitura e como esta se relaciona com o ensino da leitura na formação desses professores.

Como fundamento teórico para realização da pesquisa, parte-se da concepção da leitura como prática cultural (CHARTIER, 2001a) que se constitui inerente ao processo de formação humana, seja pelo desenvolvimento de uma educação sistematizada, na escolarização formal, seja pelas trocas sociais e comunitárias das quais os indivíduos participam. Para esta pesquisa, entende-se leitura não somente 
como ato por meio do qual se decodificam sinais gráficos, mas como processo de apreensão da realidade (FREIRE, 2003), processos que se desenvolvem no contexto da escolarização, contribuindo para que a leitura seja concebida como prática cultural escolarizada (CHARTER, 2001 a). Compreendido como prática escolarizada, o ensino de leitura constitui-se elemento fundamental a ser considerado na formação de professores de modo geral e particularmente na formação destinada aos professores dos anos iniciais de escolarização, objeto desta pesquisa.

Nesse sentido, considera-se que a obra Pedagogia da autonomia: saberes necessários à prática educativa, trabalhada na disciplina, aponta diversos saberes relevantes para a formação de professores, possibilitando, por meio de sua leitura, a apropriação das ideias pedagógicas desenvolvidas por Freire. Assim, o presente texto propõe analisar as ideias pedagógicas de Freire presentes na obra Pedagogia da autonomia: saberes necessários à prática educativa, problematizando-a com base nas seguintes questões: De que maneira a obra Pedagogia da autonomia: saberes necessários à prática educativa pode ser considerada um clássico na formação de professores? Quais ideias pedagógicas presentes na Pedagogia da autonomia contribuem para pensar sobre essa questão?

A fim de problematizar essas questões, parte-se da relação entre a concepção de clássicos defendida por Calvino e as ideias pedagógicas desenvolvidas por Freire no livro, descrevendo-o como uma obra importante para a formação de professores e como um clássico a ser lido no contexto educacional atual.

O texto será organizado explicitando os argumentos defendidos por Calvino para descrever o que este autor define para a leitura dos clássicos. Em seguida, serão apresentadas as referências sobre Paulo Freire, sua obra e os tópicos e conceitos contidos no livro Pedagogia da autonomia: saberes necessários à prática educativa. Por fim, apresenta-se uma análise das principais ideias desenvolvidas pelo autor na respectiva obra.

\section{O que é um clássico?}

O presente texto tem por objetivo analisar o livro Pedagogia da autonomia: saberes necessários à prática educativa como uma obra que, trazendo as ideias 
pedagógicas de Freire, é considerado um clássico a ser lido na formação de professores. De modo a orientar o percurso dessa reflexão, tomou-se por referência a noção de clássico elaborada por Ítalo Calvino na obra Por que ler os clássicos? descrevendo, a partir dos argumentos desenvolvidos pelo autor, as definições que contribuem para expor os significados de uma leitura clássica em educação.

Calvino (2007) apresenta as definições do que, em sua concepção, poderiam ser considerados clássicos para a leitura em diversas áreas do conhecimento, partindo do lugar de leitor ${ }^{2}$ para propor diferentes definições do que seria um clássico. Dentre as várias definições, destacam-se, para fundamentar este trabalho, as que aparecem associadas à ideia de leitor, do tempo da obra e a referência que faz à escola e sua influência na formação de leitores.

Ao considerar o leitor, Calvino (2007) afirma que ler os clássicos na juventude seria tão importante quanto ler os clássicos estando o leitor mais maduro, pois, segundo o autor, "[...] a juventude comunica o ato de ler como a qualquer outra experiência um sabor e uma importância particulares [...]". (CALVINO, 2007, p. 10) E ainda,

[...] Podem ser (talvez ao mesmo tempo) formativas no sentindo que dão uma forma às experiências futuras, fornecendo modelos, recipientes, termos de comparação, esquemas de classificação, escala de valores, paradigmas de beleza: [...] coisas que continuam a valer mesmo que nos recordemos pouco ou nada do livro lido na juventude. Relendo o livro na idade madura, acontece reencontrar aquelas constantes que já fazem parte de nossos mecanismos interiores e cuja origem havíamos esquecidos [...]. (CALVINO, 2007, p. 10)

Essas proposições marcam a posição do leitor, descrevendo as vantagens de ter lido o clássico na juventude, definida como uma experiência que se associa ao momento de descobertas, próprios desse período. Contudo, para o autor, ainda que não o tenha conhecido na juventude, ao conhecer na maturidade encontrará a obra de modo a melhor apreciá-la, pois, nessa idade, com as experiências

\footnotetext{
${ }^{2}$ Nesta obra, apresenta-se uma seleção feita por Ester Calvino de ensaios e artigos de Ítalo Calvino na qual está reunida grande parte do que o autor denominou de "seus clássicos", dentre os quais encontram-se leituras de diversas áreas, como literatura, artes e ciência. Cf. Calvino (2007).
} 
acumuladas de outras vivências e leituras, reúnem-se as melhores condições para conhecer uma obra clássica.

A referência à ideia de leitor, segundo Calvino, sugere que em qualquer tempo a apreciação de uma obra clássica constitui-se como uma leitura necessária, considerando que, se realizada ainda na juventude, a leitura dos clássicos pode ser intensificada em termos quantitativos, pois, como se costuma ter mais tempo para a leitura enquanto se é jovem, é possível que o contato com os clássicos seja maior.

Ao lado da ideia de leitor, outra referência feita por Calvino - da qual se parte para a análise - descreve que uma obra se torna um clássico pelo simples fato de que ela ainda não terminou de dizer o que tinha para dizer. Ou seja, para o autor, um clássico é uma obra que a cada nova leitura possibilita o encontro de outros sentidos, trazendo as marcas de quem precedeu nas leituras e também deixando marcas nos costumes e na linguagem das culturas por onde passou. Ao realizar a leitura de um clássico, identifica-se, segundo o autor, que há uma certa "hierarquia" entre eles, pois quem lê outros livros antes de ler o clássico reconhece seu lugar histórico.

Desse modo, Calvino destaca a importância de que é preciso definir "de onde" estão sendo lidos os clássicos. Ao apresentar essa definição, o autor destaca a importância do tempo da obra. Tempo que se refere ao momento de sua publicação e seu contexto, mas também ao fato de a obra permanecer ao longo da história sendo lida por várias gerações de leitores em quem ainda deixa marcas. Contudo, ressalta-se, segundo o autor, que um clássico é reconhecido por persistir mesmo onde predomina a atualidade mais incompatível, pois, ainda que o clássico possa não dizer nada ao tempo histórico em que é lido, ou sofra críticas de diversas ordens, ele ainda pode se constituir como clássico que diz ao momento da leitura algo que possibilita o distanciamento de seu próprio tempo.

À ideia de leitor e de tempo da obra, Calvino associa a definição de que escoIher um clássico é parte de uma leitura individual, de uma escolha pessoal, mas que a escola, com seu caráter de instituição que tem como função socializar conhecimentos, é um dos espaços que propicia a leitura dos primeiros clássicos para muitos leitores. Segundo Calvino (2007), 
[...] a escola deve fazer com que você conheça bem ou mal um certo número de clássicos dentre os quais (em relação aos quais) você poderá depois reconhecer os "seus" clássicos. A escola é obrigada a dar-lhes instrumentos para efetuar uma opção: mas as escolhas que contam são aquelas que ocorrem fora e depois de cada escola (CALVINO, 2007, p. 13).

Mesmo relacionando a escolha dos clássicos a uma tarefa particular, o autor afirma que essa escolha começa na escola e segue durante a vida dos leitores. A ênfase ao trabalho da escola, descrita por Calvino (2007), reafirma a tarefa imprescindível que ela possui para influenciar a leitura dos clássicos. Assim, entendendo a leitura como prática escolarizada (CHARTIER, 2001a), reconhece-se que o educador que lê os clássicos contribui para incentivar a leitura deles pelos seus educandos, sendo fundamental o desenvolvimento de práticas de leitura entre os educadores no contexto de formação. Nessa perspectiva, considera-se a leitura uma prática fundamental para a formação de professores, possibilitando, a partir do desenvolvimento de uma leitura crítica e de reflexões sobre a sua prática (FREIRE, 2003), que o educador reconheça o papel que ocupa de agente formador de leitores.

Assim, parte-se da leitura de uma obra que apresenta em seu título a proposição de saberes necessários à prática educativa, observando os elementos apontados por Calvino acerca de como se define um clássico, destacados como o leitor que se depara com o clássico, o tempo da obra que traz as marcas históricas e a influência que a escola tem no desenvolvimento da leitura, para explicitar as ideias de Freire e a relevância pedagógica de sua obra para a educação.

\section{Uma leitura da Pedagogia da autonomia}

Um clássico é um livro que nunca terminou aquilo que tinha para dizer.

Calvino

Inicia-se pela definição de Calvino para apresentar a Pedagogia da autonomia: saberes necessários à prática educativa, partindo-se do lugar de leitora que se assume como tal e que entrou em contato com a obra nos anos iniciais da gradua- 
ção em Pedagogia, retomando-a no doutorado em Educação. Considerar esse lugar possibilita a análise da obra com base na vivência de outras leituras.

Para este tópico, propõe-se analisar a obra Pedagogia da autonomia: saberes necessários à prática educativa, com base no questionamento: De que maneira a obra Pedagogia da autonomia: saberes necessários à prática educativa, pode ser considerada um clássico na formação de professores? Buscando-se na descrição e na explicitação dos capítulos do livro a fundamentação para elucidar a questão proposta. Contudo, antes da descrição dos capítulos do livro, faz-se necessária uma apresentação sobre o autor e sua obra, ressaltando a relevância social e pedagógica de Freire e suas ideias para a educação.

Paulo Freire foi um dos grandes educadores brasileiros cuja obra se situa, segundo Gadotti (1996), entre as mais significativas da história das ideias pedagógicas. Com formação em Direito, Freire foi professor de Língua Portuguesa, de História e Filosofia da Educação, fez da educação seu campo de atuação profissional, assumindo tarefas, nessa área, como professor e em cargos da gestão pública em educação ${ }^{3}$, sendo mundialmente reconhecido por suas obras, das quais se destacam: Educação como prática da liberdade (1967), Pedagogia do oprimido (1970), Cartas à Guiné-Bissau (1975), Ação cultural para a liberdade (1975), Educação e mudança (1979), A importância do ato de ler (1983), Prática e educação (1985), Pedagogia da esperança (1992), Professora, sim. Tia, não: carta a quem ousa ensinar (1993), À sombra da mangueira (1995), Pedagogia da autonomia: saberes necessários à prática educativa (1996).

Nessas obras, o autor apresenta as concepções que permearam suas elaborações teóricas e vivências em educação, propondo uma superação do que nomeou como "educação bancária" (FREIRE, 1987), pelo desenvolvimento de uma educação problematizadora. Destaca, no contexto da educação problematizadora, o papel da dialogicidade (FREIRE, 1987) como instrumento educativo aliado à condição de profissionalização dos educadores, enfatizando a importância da leitura de

\footnotetext{
${ }^{3}$ Paulo Freire presidiu a Comissão Nacional de Cultura Popular e coordenou o Plano Nacional de Alfabetização de Adultos (1963). Foi secretário municipal de educação de São Paulo (19891991). Cf. Gadotti (1998).
} 
mundo para aprendizagem da leitura e da escrita (FREIRE, 2003). De maneira geral, essas ideias perpassam ao longo da produção bibliográfica do autor, sendo algumas delas retomadas na obra Pedagogia da autonomia.

Optou-se por analisar as ideias da pedagogia freiriana a partir da obra Pedagogia da autonomia: saberes necessários à prática educativa, considerando ser esta a última obra do autor publicada em vida. Assim, neste tópico, apresenta-se o livro descrevendo os capítulos que o constituem.

A primeira publicação desse livro ocorreu em meados dos anos de 1990, momento em que os ideais neoliberais se ampliavam no país; em que era sancionada a Lein. 9.394, a Lei de Diretrizes e Bases da Educação Nacional (LDB), e em que se consolidavam os investimentos de grandes grupos financeiros na educação brasileira (TOMMASI; WARDE; HADDAD, 1998). Neste contexto, o destaque à autonomia dos educandos e dos educadores poderia ser considerado um risco àqueles que defendiam uma prática progressista em educação; contudo, apostar na autonomia era, de acordo com Freire (2010), uma das alternativas de escapar ao que era apontado no projeto neoliberal para a educação, cujos princípios propunham o esvaziamento dos sentidos educativos.

A obra divide-se em três capítulos. Neles, Freire apresenta, como evidenciado no título, enunciados que trazem saberes essenciais à prática educativa. Ao longo do texto, esses saberes são explicitados tendo como destinatários principais os professores. Essa questão é posta no início do texto, pelo autor, ao afirmar que a formação docente se constitui como tema central do texto em torno do qual giram os outros temas, como a ética, a transformação social pela educação, a potencialidade da reflexão crítica, o diálogo e o respeito à autonomia dos educandos.

Em cada um dos capítulos, Freire apresenta ideias gerais que são explicitadas em forma de saberes identificados como necessários à ação docente. As proposições apresentadas pelo autor referem-se ao reconhecimento de que não há docência sem discência, que educar não é transferir conhecimentos e que ensinar é uma especificidade humana. Definindo essas proposições como capítulos da obra, o autor reafirma a necessidade de cuidar da relação pedagógica, de ampliar 
os conhecimentos que são aprendidos no processo e de compreender a educação como atividade humana.

Neste tópico, serão explicitadas de modo mais detalhado as proposições apresentadas e os saberes que sustentam cada uma dessas proposições. No primeiro capítulo, Freire descreve a importância da interação dos sujeitos na relação pedagógica. Nessa relação, é necessário que o educando se reconheça como sujeito, pois, segundo Freire, nem mesmo o ensino bancário pode lhe colocar no lugar de "não-sujeito", porque o próprio ato de aprender contribui para superar o autoritarismo desse ensino. Segundo o autor, a "[...] formação criadora de que fazem parte a comparação, a repetição, a constatação, a dúvida rebelde, a criatividade não facilmente satisfeita, [...] supera os efeitos negativos do falso ensino". (FREIRE, 1996, p. 25)

A prática educativa defendida por Freire é a prática educativo-crítica ou prática progressista, e o que ele propõe no livro é alinhar e discutir alguns saberes fundamentais como conteúdos obrigatórios para a formação docente. Nesse processo, é necessário que se alinhe o papel do professor na relação pedagógica, pois, conforme Freire, "[...] não há docência sem discência, as duas se explicam e seus sujeitos, apesar das diferenças que os conotam, não se reduzem à condição de objeto, um do outro [...]. (FREIRE, 1996, p. 23)

Desse modo, o reconhecimento da relação entre educador e educando requer um conjunto de saberes que contribuem para sustentar essa relação. Dentre os saberes apontados, Freire destaca que uma das atividades primordiais dos educadores é "[...] trabalhar com os educandos a rigorosidade metódica com que devem se 'aproximar' dos objetos cognoscíveis [...]" (FREIRE, 1996, p. 26), pois considera que o educador teve e continua tendo experiências na produção de saberes que não podem ser transferidos aos educandos, mas que devem torná-los inquietos e rigorosamente curiosos.

Os saberes descritos por Freire estabelecem relações entre si, por isso o rigor metodológico associa-se à necessidade de pesquisa, que é inerente, conforme o autor, ao ato de ensinar.

[...] Ensino porque busco, porque indaguei, porque indago e me indago. Pesquiso para constatar, constatando, intervenho, intervindo, 
educo e me educo. Pesquiso para conhecer o que ainda não conheço e comunicar ou anunciar a novidade. (FREIRE, 1996, p. 29)

A necessidade de busca constante por conhecer, por saberes que precisam ensinar faz com que o educador se reconheça como aprendiz, que demonstre respeito aos saberes que os educandos trazem de suas experiências, considerando que os saberes socialmente construídos na prática comunitária se relacionam ao ensino dos conteúdos difundidos no contexto escolar.

Outros saberes apontados por Freire incluem a busca da ética e da estética no processo educativo, sugerindo a demonstração desses saberes por meio do exemplo no contexto de ensino e aprendizagem; e também a rejeição a qualquer forma de discriminação e a aceitação do novo, demonstradas pelo autor como atitudes que colocam na relação pedagógica o reconhecimento do educador e dos educandos como sujeitos éticos.

Ainda no primeiro capítulo, o autor destaca a reflexão crítica como um instrumento fundamental para a prática educativa e, por isso, sugere inseri-la na formação de professores. Promover a criticidade é, segundo Freire, uma das finalidades do processo educativo. Assim, "nenhuma formação docente verdadeira pode fazer-se alheada, de um lado, do exercício da criticidade que implica a promoção da curiosidade ingênua à curiosidade epistemológica [...]". (FREIRE, 1996, p. 45)

O segundo capítulo traz uma importante proposição: ensinar não é transferir conhecimento. Nele, Freire descreve a importância de, na formação docente, o educador reconhecer que, ao ensinar, precisa compreender que este ato não ocorre somente pela transmissão de conteúdos, mas que os conteúdos são o ponto de partida para criar diferentes possibilidades de socialização e problematização no contexto do ensino e da aprendizagem.

Na obra, Freire aponta que a tomada de consciência de ambos (educador e educandos) contribui para reafirmar a conscientização como exigência humana e um dos caminhos para pôr em prática a curiosidade epistemológica.

Dentre os saberes destacados pelo autor neste capítulo estão o bom-senso, a humildade, a tolerância, a luta pelos direitos dos educadores e a apreensão da realidade, definindo-a como atividade criadora que, para além da memorização mecânica do objeto, contribui para a reconstrução deste como objeto de conheci- 
mento, produzindo-se a partir dele novos significados. Para Freire, esses saberes envolvem um conjunto de informações que articulam fundamentos teóricos e vivências refletidas de maneira crítica.

A apreensão da realidade como saber necessário à formação docente articula-se com outro que se refere à curiosidade. Esta, por sua vez, é considerada pelo autor um exercício que importa tanto aos professores como aos alunos.

[...] o bom professor é o que consegue, enquanto fala, trazer o aluno até a intimidade do movimento de seu pensamento. Sua aula é assim um desafio e não uma 'cantiga de ninar'. Seus alunos cansam, não dormem. Cansam porque acompanham as idas e vindas de seu pensamento, surpreendem suas pausas, suas dúvidas, suas incertezas. (FREIRE, 1996, p. 86)

O estímulo ao pensamento curioso produz um efeito de apreensão da realidade, pois impulsiona a aprendizagem para o lugar da busca, da descoberta de conhecimentos que, para serem aprendidos, são estudados com rigor, conhecendo-se em profundidade o objeto da aprendizagem. Ao propor o desenvolvimento da curiosidade, Freire trata de uma passagem da curiosidade espontânea para a curiosidade epistemológica, entendendo que,

O exercício da curiosidade convoca a imaginação, a intuição, as emoções, a capacidade de conjecturas, de comparar, na busca da perfilização do objeto ou do achado de sua razão de ser. Um ruído, por exemplo, pode provocar minha curiosidade. Observo o espaço onde parece que se está verificando. Aguço o ouvido, procuro comparar com outro ruído cuja razão de ser já conheço. Investigo melhoro espaço. Admito hipóteses várias em torno da possível origem do ruído. Elimino algumas até que chego a sua explicação. (FREIRE, 1996, p. 88)

O caminho proposto pelo autor parte da curiosidade ingênua que, na interação com o objeto, vai produzindo uma abertura a conhecê-lo. Isso se faz, segundo o autor, envolvendo procedimentos que necessitam do rigor metodológico e da condução que o educador dá ao processo.

No terceiro capítulo, Freire discorre sobre o ato de ensinar como uma especificidade humana e, por essa especificidade, propõe saberes envolvendo a competência profissional dos educadores que, de acordo com o autor, seria impossível de separar "[...] o ensino dos conteúdos da formação ética dos educandos [...]" 
(FREIRE, 1996, p. 95). Saber que exige comprometimento, entendendo a educação como uma forma de intervenção no mundo, que exige liberdade, autoridade e escuta como processo pedagógico.

Neste último capítulo, Freire reafirma que o compromisso do educador pressupõe o querer bem dos educandos, ressaltando a afetividade como o elemento capital para a formação humana, sugerindo que seja respeitada no processo educativo. De acordo com Freire, "[...] A afetividade não se acha excluída da cognoscibilidade [...]" (FREIRE, 1996, p. 141), por isso o educador que considera a afetividade um elemento constitutivo do ato educativo respeita o educando, possibilitando que a aproximação entre os sujeitos contribua para o desenvolvimento de ambos.

De maneira geral, nos três capítulos do livro, Freire apresenta concepções em que descreve saberes necessários à formação docente, tendo como interlocutor principal os educadores. Estejam eles em exercício da função, em formação, ou ainda porque educandos podem vir a ser educadores. Nesse sentido, destaca-se que a apropriação das ideias pedagógicas por meio da leitura da obra contribui para a compreensão desses enunciados como elementos importantes para reflexões e vivências na prática educativa.

Retomando a citação apresentada no início deste tópico, "Um clássico é um livro que nunca terminou aquilo que tinha para dizer" (CALVINO, 2007, p.11), ressalta-se que a exposição de algumas das ideias contidas no livro e em outras obras do autor contribui para reforçar a noção de clássico trazida nessa definição. Nesse sentido, considera-se importante explicitar as ideias pedagógicas que, apresentadas no livro em análise, contribuem para reiterá-lo como obra clássica na formação de professores.

\footnotetext{
${ }^{4} \mathrm{O}$ conceito de apropriação é entendido a partir do que defende Chartier (2001 a) referindo-se a um processo criativo e inventivo que permite uma relação entre quem se apropria e o objeto que foi apropriado, numa troca em que ambos deixam marcas um no outro, considerando que estas dependem da identidade sócio-histórica de cada leitor e da comunidade na qual ele está inserido. Cf. Chartier (2001b).
} 
Apropriações ${ }^{4}$ das ideias pedagógicas na Pedagogia da autonomia: saberes necessários à prática educativa

Toda releitura de um clássico é uma leitura de descoberta como a primeira.

Após uma revisão dos capítulos e das ideias apresentadas pelo autor, neste tópico serão apresentadas as ideias que se destacam como centrais ao longo da obra. Parte-se da questão apresentada no início do texto que interroga acerca das ideias que contribuem para pensar o livro como uma obra clássica na formação de professores. Na tentativa de problematizar o referido questionamento, buscou-se definir as ideias, utilizando-se como critérios: a recorrência ao longo do texto; a retomada em outros trabalhos do autor e ideias que explicitam o contexto de publicação da obra.

A partir dos critérios apresentados, destacam-se, nesta análise, três ideias centrais da Pedagogia da autonomia. A primeira refere-se à educação pelo diálogo, a segunda descreve a associação entre o rigor metodológico e a dimensão ética e a terceira refere-se ao desenvolvimento da autonomia dos educandos.

A opção pelas ideias expostas neste tópico tem por base as apropriações realizadas durante o estudo da obra e serão apresentadas por meio de enunciados que as explicitam. Assim, inicia-se pela ideia a respeito do desenvolvimento da autonomia: primeiro porque ela se constitui como temática central do livro; depois por se apresentar como ideia que reflete o contexto sociopolítico do momento em que o livro foi publicado, fazendo-se necessária uma apresentação desse contexto - uma vez que a obra é analisada, segundo Calvino, na perspectiva do tempo em que foi elaborada.

\section{O desenvolvimento da autonomia dos educandos}

O livro Pedagogia da autonomia: saberes necessários à prática educativa teve sua primeira edição na segunda metade dos anos de 1990. Nesse momento, as 
políticas neoliberais ganhavam sustentação no governo brasileiro e, influenciadas pelos investimentos financeiros, atuavam na educação de forma a definir os currículos, as avaliações e o financiamento educacional (TOMMASI; WARDE; HADDAD, 1998). A respeito desse contexto, Freire afirma que "[...] o discurso da globalização que fala da ética esconde, porém, que a sua é a ética do mercado e não a ética universal do ser humano, pela qual devemos lutar bravamente se optamos, na verdade, por um mundo de gente [...]". (FREIRE, 1996, p. 127)

Presente no discurso neoliberal, a autonomia era defendida como princípio nos pilares ${ }^{5}$ da educação, de modo a promover o desenvolvimento da aprendizagem voltando-se para o aluno como sujeito de seu próprio processo.

Em meio a essa perspectiva de autonomia caracterizada pelos ideais neoliberais, Freire aponta para a necessidade de desenvolvimento da autonomia dos educandos como uma importante tarefa a ser realizada em conjunto com o educador. Nesse sentido, a autonomia de que trata o autor se difere da preconizada pelos ideais neoliberais por considerar que "o educando vá sendo artífice de sua formação com a ajuda necessária do educador [...]". (FREIRE, 1996, p. 71)

A autonomia proposta no livro em análise a reconhece como um princípio que parte do respeito aos sujeitos envolvidos no processo educativo. Para Freire (1996), promover a autonomia dos educandos significa possibilitar o desenvolvimento do pensar a partir dos sujeitos que se encontram inseridos no processo, ou seja, educadores e educandos. Nessa perspectiva, para promover a autonomia dos educandos, estes contam com o trabalho dos educadores que precisam oferecer conhecimentos, condições e situações, possibilitando aos educandos a reflexão crítica, o desenvolvimento do pensar e o agir a partir de suas próprias decisões.

Segundo o autor, o respeito ao desenvolvimento da autonomia como princípio pedagógico advém da importância que ela tem para a existência

\footnotetext{
${ }^{5}$ O relatório "Educação: um tesouro a descobrir", publicado pela UNESCO em 1996 apresenta como pilares da educação: Aprender a ser - Aprender a fazer - Aprender a conhecer Aprender a conviver, articulando o ato de aprender ao processo de desenvolvimento de aprendizagem do aluno. Cf. Delors (1996).
} 
humana. Desse modo, defende que "[...] o respeito à autonomia e à dignidade de cada um é um imperativo ético e não um favor que podemos ou não conceder uns aos outros [...]". (FREIRE, 1996, p. 59)

Compreender o desenvolvimento da autonomia como exercício constante presente no ato educativo contribui para considerar que a autonomia de pensamento do educando possibilita também ao educador pensar sobre sua própria autonomia, pois a prática educativa demanda a existência de sujeitos que, ensinando, aprendem e que, aprendendo, ensinam. A autonomia é, nesta obra, compreendida como o propósito da educação, pois se ensina algo a alguém para que este possa realizar a tarefa que Ihe foi ensinada e, a partir daí, possa se desenvolver em todas as suas potencialidades.

\section{Entre o rigor metodológico e a dimensão ética}

Outra ideia defendida por Freire se refere à associação entre o rigor metodológico e a dimensão ética. Compreende-se o rigor metodológico como uma das principais tarefas dos educadores, pois se destina a apreensão do objeto de conhecimento e sua aproximação dos educandos. Contudo, é importante destacar que, para Freire, o ensino não se esgota na transmissão dos conteúdos, por isso ele aponta que rigorosidade metódica associa-se à dimensão ética.

Ao apresentar o rigor metódico como um saber necessário ao desenvolvimento da prática educativa, Freire propõe a seguinte reflexão: "[...] Como alfabetizar sem conhecimentos precisos sobre a aquisição da linguagem, sobre linguagem e ideologia, sobre técnicas e métodos de ensino de leitura e escrita?". (FREIRE, 1996, p. 81)

Dessa reflexão, considera-se a importância de o educador propor situações de ensino e aprendizagem que aproximem os educandos do objeto de ensino, levando em conta que este se constitui como parte inerente ao processo de ensino e aprendizagem, pois conhecer o que vai ensinar demonstra o comprometimento do educador com os educandos, e isso corresponde a uma das condições básicas e que constituem a atividade docente. 
Pesquisar sobre o objeto de sua área de ensino, organizar e preparar as atividades aos educandos são tarefas que o educador realiza de modo a aproximálos do objeto cognoscível. Entretanto, para Freire, promover o desenvolvimento do pensamento crítico dos educandos vai além de um ensino que trabalhe somente com a memorização de conteúdos, pois ele reconhece a importância de despertar atitudes de concentração, atenção e decodificação que ampliem a leitura de mundo desses sujeitos.

[...] O intelectual memorizador, que lê horas a fio, domesticando-se ao texto, temeroso de arriscar-se, fala de suas leituras quase como se estivesse recitando-as de memória-não percebe, quando realmente existe, nenhuma relação entre o que leu e o que vem ocorrendo no seu país, na sua cidade, no seu bairro [...]. (FREIRE, 1996, p. 27)

O respeito à dignidade do educando e à realidade em que ele vive precisam ser reconhecidos pelos educadores como saberes que contribuem para 0 desenvolvimento de suas potencialidades e deve ser pensado de modo a superar a condição de que "[...] a realidade com que eles têm que ver é a realidade idealizada de uma escola que vai virando cada vez mais um dado aí, desconectado do concreto [...]". (FREIRE, 1996, p. 27)

Ao contrário, associar o rigor metodológico à dimensão ética contribui para que o conhecimento produzido seja socializado levando em conta as finalidades éticas, promovendo saberes para que, de posse desses conhecimentos, os sujeitos possam intervir na sociedade. Desse modo, o rigor do ensino que gera a disciplina intelectual associa-se a partir da proposição de Freire ao desenvolvimento da capacidade dos educandos de reconhecerem-se no mundo e, como seres históricos, intervirem na realidade que estão inseridos, compreendendo que os conhecimentos que são aprendidos devem também ser apreendidos a partir da relação que têm com a realidade.

\section{Educar para o diálogo}

Outra ideia pedagógica a ser destacada nesta análise refere-se à educação para o diálogo que, descrita ao longo da bibliografia de Freire, é retomada no livro Pedagogia da autonomia: saberes necessários à prática educativa. 
Na Pedagogia do oprimido, Freire (1987) aponta o diálogo como uma exigência da existência humana, "[...] em um encontro em que se solidarizam o refletir e o agir de sujeitos [...]". (FREIRE, 1987, p. 79) Na obra em análise, o autor situa a disponibilidade para o diálogo como saber relevante à formação docente.

O diálogo é apresentado no livro como processo metodológico que pode aparecer durante as atividades de ensino e aprendizagem, em momentos explicativos encaminhando o debate sobre conteúdos, saberes e práticas no ato educativo. De acordo com Freire, "[...] a dialogicidade não nega a validade de momentos explicativos, narrativos em que o professor expõe ou fala do objeto [...]" (FREIRE, 1996, p. 86), enfatizando que "[...] o que importa é que o professor e alunos se assumam epistemologicamente curiosos [...]". (FREIRE, 1996, p. 86) Ao educar pelo diálogo, o professor possibilita a troca de experiências com os educandos, permitindo por meio da escuta do outro a leitura de mundo em que o outro vive, a escuta atenciosa que, promovida pelo diálogo, proporciona ao educador conhecer os anseios, as dificuldades e as potencialidades dos educandos.

Colocar-se disponível para o diálogo possibilita a aceitação às diferenças de pensar, o respeito às escolhas que foram feitas pelos sujeitos e a abertura aos costumes, às diferentes realidades das quais advém os educandos. Para Freire, "O sujeito que se abre ao mundo e aos outros inaugura com seu gesto a relação dialógica [...]". (FREIRE, 1996, p. 136) Assim, educar para o diálogo permite ao educador abrir-se à realidade de seus educandos, partilhando com eles a compreensão de sua realidade, diminuindo as distâncias que impossibilitam o desenvolvimento da relação dialógica.

\section{Considerações}

É clássico aquele que persiste como rumor mesmo onde predomina a atualidade mais incompatível.

Diante do que foi explicitado ao longo do texto, é importante ressaltar as questões iniciais que contribuíram para orientá-lo. Apresentaram-se dois 
questionamentos que foram descritos da seguinte forma: De que maneira a obra Pedagogia da autonomia: saberes necessários à prática educativa pode ser considerada um clássico na formação de professores? Quais ideias pedagógicas presentes na Pedagogia da autonomia contribuem para pensar sobre essa questão? A partir dessas questões, buscou-se, sem a pretensão de esgotá-las, explicitar as concepções de clássico defendidas por Calvino e que contribuíram para fundamentar a leitura da Pedagogia da autonomia: saberes necessários à prática educativa como leitura necessária à formação docente.

Reconhecer a importância da leitura das ideias pedagógicas de Freire contribui para a compreensão de que em nenhum outro momento da história política do país a leitura desse autor se fez tão necessária. Retomando as citações sobre os clássicos apresentadas ao longo do texto, descreveu-se como clássico aquele que nunca terminou de dizer o que tinha para dizer, aquele cuja releitura é uma leitura de descoberta como a primeira e a que inicia este tópico, considerando que uma das tarefas de um clássico é deixar ruídos em tempos e contextos mesmo que estes sejam incompatíveis com as suas ideias.

Considera-se a relevância da obra Pedagogia da autonomia: saberes necessários à prática educativa porque nela se encontram ideias defendidas por Freire ao longo de sua bibliografia, o que contribui para dar sustentação teórica ao pensamento da pedagogia freiriana. Ao tratar da educação pelo diálogo, da valorização do pensamento crítico, do desenvolvimento da autonomia, da necessária disciplina intelectual, o autor aponta para a concepção de educação que se propõe à transformação social - princípio necessário à prática educativa em todos os tempos, mas de maneira especial no contexto atual da educação nacional, em que reiteradas ofensas são imputadas ao ato de educar, às instituições educativas e aos sujeitos que nelas atuam.

Nesse sentido, a relevância da obra de Freire pode ser demonstrada também pela definição da educação como ato político. Segundo o autor, é preciso despertar nos educadores o querer bem aos educandos, a partir da aceitação das diferenças, do respeito aos conhecimentos destes como sujeitos, assumindo o comprometimento com eles. Freire aponta para a seguinte reflexão: "Em favor de 
que estudo? Em favor de quem? Contra que estudo? Contra quem estudo?". (FREIRE, 1996, p. 77) Parafraseando o autor, acrescenta-se a estes, outro questionamento: Em favor de que e de quem pesquiso? Essas questões precisam ser, constantemente, postas em diálogo entre os educadores, a fim de que seja possível orientá-los para uma leitura que os encaminhe numa perspectiva crítica de educação e de sociedade. 


\section{Referências Bibliográficas}

CALVINO, Ítalo. Por que ler os clássicos? Tradução: Nilson Moulin. São Paulo: Companhia da Letras, 2007.

CHARTIER, Roger (org.). Práticas da leitura/ sob a direção de Roger Chartier: uma iniciativa de Alain Paire. Tradução: Cristiane Nascimento, 2. ed. São Paulo: Estação Liberdade, 2001a.

CHARTIER, Roger. Cultura escrita, literatura e história: conversas de Roger Chartier com Carlo Aguirre Anaya, Jesús Anaya Rosique, Daniel Goldin e Antonio Saborit. Porto Alegre: Artmed, $2001 \mathrm{~b}$.

DELORS, Jacques (org.). Educação: um tesouro a descobrir. Relatório para a UNESCO da Comissão Internacional sobre educação para o século XXI. São Paulo: Cortez, 1996.

FREIRE, Paulo. Pedagogia do oprimido.17. ed. Rio de Janeiro: Paz e Terra, 1987.

FREIRE, Paulo. A importância do ato de ler: em três artigos que se completam. 45. ed. São Paulo: Cortez, 2003.

FREIRE, Paulo. Pedagogia da autonomia: saberes necessários à prática educativa. São Paulo: Paze Terra, 1996.

GADOTTI, Moacir (org.). Paulo Freire: uma biobibliografia. São Paulo: Cortez, 1996.

GADOTTI, Moacir. História das ideias pedagógicas. 6. ed. São Paulo: Ática, 1998.

TOMMASI, Lívia de; WARDE, Mirian Jorge; HADDAD, Sergio (org.). O banco mundial e as políticas educacionais. 2. ed. São Paulo: Cortez, 1998. 